\title{
EPIDEMIOLOGY OF PELVIC FRACTURES AND CONCOMITANT INJURIES- A CROSS-SECTIONAL OBSERVATIONAL STUDY
}

\author{
Lalatendu Swain ${ }^{1}$, Prabhat Nalini Rautray2, Mamata Singh ${ }^{3}$
}

${ }_{1}^{1}$ Associate Professor, Department of Anatomy, GMC and H, Balasore, Odisha, India.

${ }^{2}$ Assistant Professor, Department of Radiodiagnosis, GMC and H, Balasore, Odisha, India.

${ }^{3}$ Assistant Professor, Department of Radiodiagnosis, SCB MC and H, Cuttack, Odisha, India.

\section{ABSTRACT}

\section{BACKGROUND}

Pelvic fractures are rare injuries (3 - 8\%) as compared with fractures in other body regions. Often the result of high-energy trauma in young individuals and low-energy injury in older people, pelvic ring fractures are associated with considerable morbidity, high mortality rates and significant cost to the society.

\section{MATERIALS AND METHODS}

This study was a retrospective descriptive study analysis of data of trauma patients with pelvic fractures admitted in the Emergency Room (ER). The diagnosis of a fracture was based on the history, signs and symptoms, visual finding, manual examination and OPG radiographs. Exact determination of site and pattern of bony injury was determined by correlating it radiographically using three dimensional CT scan.

\section{RESULTS}

We conducted this study on 130 patients who presented to the emergency department and diagnosed radiologically to have some type of pelvic fracture. Out of 130 patients, $37.7 \%$ were males and $62.3 \%$ were females. Majority of fractures were seen in the elderly age group of $>75$ years $(50.8 \%)$.

\section{CONCLUSION}

Pelvic fractures are often the result of high-energy trauma in young individuals and low-energy injury in older people. Often associated with injuries at other multiple sites increasing morbidity and mortality.

\section{KEY WORDS}

Pelvic Fracture, Solid Organ Injury, Road Traffic Accident, Urethral Injury.

HOW TO CITE THIS ARTICLE: Swain L, Rautray PN, Singh M. Epidemiology of pelvic fractures and concomitant injuries- a crosssectional observational study. J. Evolution Med. Dent. Sci. 2018;7(40):4331-4335, DOI: 10.14260/jemds/2018/966

\section{BACKGROUND}

Pelvic fractures are rare injuries $(3-8 \%)$ as compared with fractures in other body regions, ${ }^{1}$ although the frequency may be as high as $25 \%$ in patients with multiple trauma. ${ }^{2}$ Often the result of high-energy trauma in young individuals ${ }^{2}$ and low-energy injury in older people, ${ }^{3}$ pelvic ring fractures are associated with considerable morbidity, high mortality rates and significant cost to the society. ${ }^{4}$ With an aging population, the burden of low-energy pelvic fractures will likely continue to affect a growing number of individuals. ${ }^{5}$ Most deaths in patients with pelvic fractures are not caused by the pelvic fracture itself, but are linked to associated injuries. ${ }^{1}$ Fatal pelvic injury patients die at a median of 2 days after the trauma. 6 A meta-analysis consisting of twelve studies with a total of 5,454 pelvic fracture patients concluded that in stable and alert trauma patients a thorough clinical examination will detect pelvic fractures with nearly $100 \%$ sensitivity, thus rendering initial radiography unnecessary in this group of patients. ${ }^{7}$

'Financial or Other Competing Interest': None.

Submission 24-08-2018, Peer Review 18-09-2018,

Acceptance 24-09-2018, Published 01-10-2018.

Corresponding Author:

Dr. Lalatendu Swain,

Flat No. 104, Metro Manorama Complex,

Kathagola Street, Mangalabag,

Cuttack-753001, Odisha, India.

E-mail: lalatenduswain1975@gmail.com

DOI: $10.14260 /$ jemds $/ 2018 / 966$

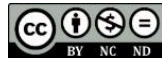

Due to the increase of older population worldwide,$^{8}$ the burden of pelvic fractures will become highly relevant for society in general and in particular for our healthcare systems. Consequently, low energy fractures are assumed to affect a growing number of individuals and an increase of pelvic fracture incidences has already been reported. From the viewpoint of pre-hospital emergency medical management for injured people, identification of pelvic fractures in those with stable or unstable vital signs is critical. Furthermore, evaluation of possible associated injuries is still important, even though the greater proportion of pelvic fractures are not of a life-threatening status. Comprehensive epidemiologic surveillance of pelvic fractures with other combined injuries could provide sufficient information to pre-hospital or in-hospital medical staff to improve emergency management and enable policymakers to consider alternative resources and training programs.

The objective of this study was to determine the types, aetiological factors and associated injuries of pelvic fracture.

\section{MATERIALS AND METHODS}

This study was a retrospective descriptive study analysis of data of trauma patients admitted in the emergency room (ER) of SCB Medical College and Hospital, Cuttack and Govt. Medical College and Hospital, Balasore, Odisha, India, during the period from August 2017 to July 2018. Patients with pelvic fractures were included in the study. The diagnosis of a fracture was based on the history, signs and symptoms, visual finding, manual examination and OPG radiographs. Exact 
determination of site and pattern of bony injury was determined by correlating it radiographically using three dimensional CT scan. In our study, based on the documented radiographic findings, the fracture sites were assigned to one of four anatomical subsites including pubis, ilium, ischium and sacrum. The aetiological factors were classified as Road Traffic Accidents (RTA), fall from height, pedestrian hit by car, assault and others. Age, gender, aetiology, pattern of pelvic fractures and associated injuries were recorded in clinical proforma.

\section{RESULTS}

We conducted this study on 130 patients who presented to the emergency department and diagnosed radiologically to have some type of pelvic fracture. Out of 130 patients, 49 $(37.7 \%)$ were males and 81 (62.3\%) were females. Females sustained significantly more injuries as compared to males with an overall ratio of 1.7: 1 (Graph 1).

\section{Gender wise distribution}

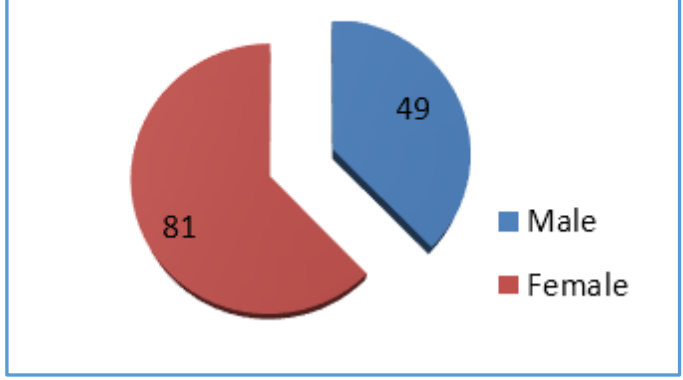

Graph 1. Gender Wise distribution of Cases

Majority of fractures are seen in the elderly age group of $>75$ years, 66 (50.8\%) followed by < 35 years, 25 (19.2\%), 56-75 years, $23(17.7 \%)$ and 36 - 55 years, $16(12.3 \%)$ of life. In patients aged above 55 years of age, there was more incidence of fractures that accounts for $68.5 \%$ (Graph 2).

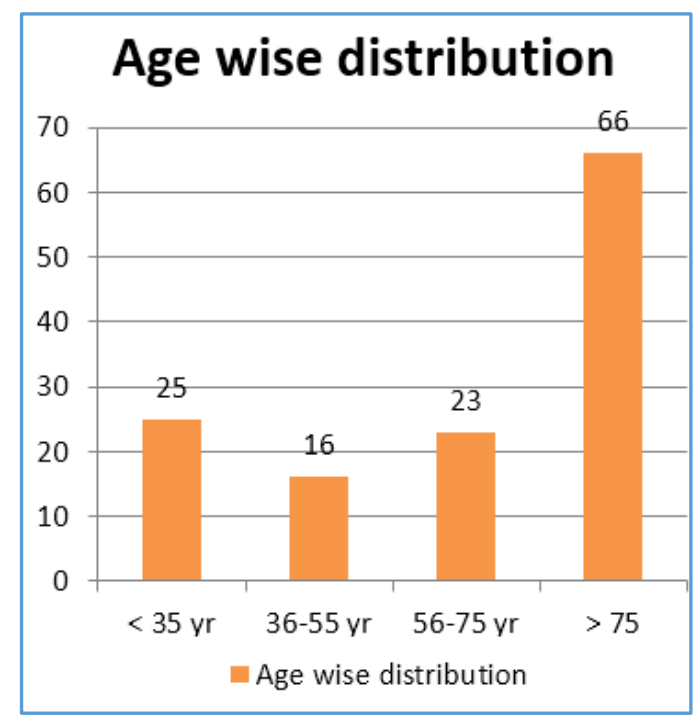

Graph 2. Age Wise distribution of Cases

Among 130 patients with pelvic fractures pubis fracture was seen in maximum number of cases, $88(67.7 \%)$ followed by ilium in $83(63.8 \%)$, ischium in $61(46.9 \%)$ and sacrum in $21(42.9 \%)$ cases. Multiple pelvic ring fracture (more than 2 fracture sites) were seen in 23 (17.8\%) cases (Table 1$)$.

\begin{tabular}{|c|c|c|c|c|c|c|c|}
\hline \multicolumn{2}{|r|}{ 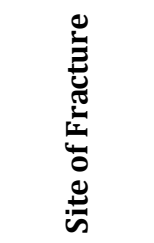 } & 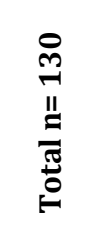 & 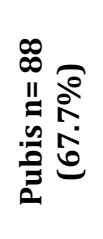 & 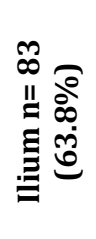 & 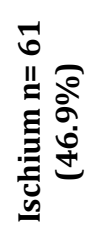 & 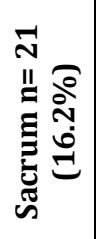 & 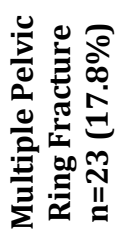 \\
\hline \multirow{2}{*}{$\frac{\bar{d}}{\frac{\delta}{d}}$} & Male & $\begin{array}{c}49 \\
(37.7) \\
\end{array}$ & $\begin{array}{c}21 \\
(23.9)\end{array}$ & $\begin{array}{c}48 \\
(57.8) \\
\end{array}$ & $\begin{array}{c}14 \\
(29.5)\end{array}$ & $\begin{array}{c}8 \\
(38.1) \\
\end{array}$ & $\begin{array}{c}13 \\
(56.5) \\
\end{array}$ \\
\hline & Female & $\begin{array}{c}81 \\
(62.3) \\
\end{array}$ & $\begin{array}{c}67 \\
(76.1)\end{array}$ & $\begin{array}{c}35 \\
(42.2) \\
\end{array}$ & $\begin{array}{c}43 \\
(70.5) \\
\end{array}$ & $\begin{array}{c}13 \\
(61.9) \\
\end{array}$ & $\begin{array}{c}10 \\
(43.5)\end{array}$ \\
\hline \multirow{4}{*}{ Ë } & $\begin{array}{l}<35 \\
\text { Yrs. }\end{array}$ & $\begin{array}{c}25 \\
(19.2)\end{array}$ & $\begin{array}{c}17 \\
(19.3)\end{array}$ & $\begin{array}{c}23 \\
(27.7) \\
\end{array}$ & $\begin{array}{c}9 \\
(14.8)\end{array}$ & $\begin{array}{c}7 \\
(33.3) \\
\end{array}$ & $\begin{array}{c}7 \\
(30.4)\end{array}$ \\
\hline & $\begin{array}{c}36-55 \\
\text { yrs. }\end{array}$ & $\begin{array}{c}19 \\
(15.4)\end{array}$ & $\begin{array}{c}8 \\
(9.1) \\
\end{array}$ & $\begin{array}{c}12 \\
(14.5) \\
\end{array}$ & $\begin{array}{c}7 \\
(11.5) \\
\end{array}$ & $\begin{array}{c}5 \\
(23.8) \\
\end{array}$ & $\begin{array}{c}8 \\
(34.8) \\
\end{array}$ \\
\hline & $\begin{array}{c}56-75 \\
\text { yrs. }\end{array}$ & $\begin{array}{c}20 \\
(8.6)\end{array}$ & $\begin{array}{c}14 \\
(15.9)\end{array}$ & $\begin{array}{c}17 \\
(20.5)\end{array}$ & $\begin{array}{c}10 \\
(16.4)\end{array}$ & $\begin{array}{c}3 \\
(14.3)\end{array}$ & $\begin{array}{c}3 \\
(13.1)\end{array}$ \\
\hline & $\begin{array}{l}>75 \\
\text { Yrs. }\end{array}$ & $\begin{array}{c}66 \\
(50.8) \\
\end{array}$ & $\begin{array}{c}49 \\
(55.7)\end{array}$ & $\begin{array}{c}31 \\
(37.3) \\
\end{array}$ & $\begin{array}{c}35 \\
(57.4)\end{array}$ & $\begin{array}{c}6 \\
(28.6) \\
\end{array}$ & $\begin{array}{c}5 \\
(23.8) \\
\end{array}$ \\
\hline
\end{tabular}

Table 1. Distribution of Cases according to Site of Fracture

Fractures due to RTAs is most commonly seen in 73 (56.2\%) cases followed by fall from height in 29 (22.3\%), pedestrian hit by car in $18(13.8 \%)$, assault injury in $6(3.4 \%)$ and others 4 (3\%) cases (Table 2).

\begin{tabular}{|c|c|c|}
\hline Aetiology & $\mathbf{n = 1 3 0}$ & $\mathbf{\%}$ \\
\hline Road traffic accident & 73 & 56.2 \\
\hline Fall from height & 29 & 22.3 \\
\hline Pedestrian hit by car & 18 & 13.8 \\
\hline Assault & 6 & 3.4 \\
\hline Others & 4 & 3 \\
\hline
\end{tabular}

Table 2. Distribution of Cases according to their Aetiology

Pelvic fractures are associated with other injuries in 75 (57.7\%) cases. Most commonly associated injury was urinary bladder and urethral injury in $45(34.7 \%)$ cases followed by Solid Organ Injury (SOI) in 35 (26.9\%), chest trauma with rib fractures in 24 (18.5\%), haemodynamic instability in 19 (14.6\%), lung contusion in $15(11.5 \%)$ cases and other injuries observed were Acetabular fracture, Femur fracture, head injury and Facial bone fractures. Among the solid organs, most common organ involved was splenic in 16 $(12.3 \%)$ followed by liver in $12(9.2 \%)$ and kidney in 8 $(6.2 \%)$ cases (Table 3).

\begin{tabular}{|c|c|c|c|}
\hline \multicolumn{2}{|c|}{ Associated Other Injury, n= 75 (57.7\%) } & $\mathbf{n}=130$ & $\%$ \\
\hline \multicolumn{2}{|c|}{ Urinary bladder and Urethral injury } & 45 & 34.7 \\
\hline \multirow{3}{*}{$\begin{array}{c}\text { Solid Organ } \\
\text { Injury (SOI) } \\
n=35 \\
(26.9 \%) \\
\end{array}$} & Splenic injury & 16 & 12.3 \\
\hline & Liver injury & 12 & 9.2 \\
\hline & Kidney injury & 7 & 5.4 \\
\hline \multicolumn{2}{|c|}{ Chest trauma with rib fracture } & 24 & 18.5 \\
\hline \multicolumn{2}{|c|}{ Haemodynamic instability } & 19 & 14.6 \\
\hline \multicolumn{2}{|c|}{ Lung contusion } & 15 & 11.5 \\
\hline \multicolumn{2}{|c|}{ Acetabular fracture } & 14 & 10.8 \\
\hline \multicolumn{2}{|c|}{ Femur fracture } & 11 & 8.5 \\
\hline \multicolumn{2}{|c|}{ Femoral neck fracture } & 8 & 6.2 \\
\hline \multicolumn{2}{|c|}{ Head injury } & 3 & 2.3 \\
\hline \multicolumn{2}{|c|}{ Facial bone fracture } & 4 & 3.1 \\
\hline \multicolumn{4}{|c|}{$\begin{array}{c}\text { Table 3. Distribution of Cases of Pelvic Fracture and } \\
\text { associated Other Injury }\end{array}$} \\
\hline
\end{tabular}


Incidence of solid organ injury was more in patients associated with rib fracture in comparison to patients with only pelvic fracture (66.7\% vs. $21.7 \%$ ) (Table 4$)$.

\begin{tabular}{|c|c|c|}
\hline $\begin{array}{c}\text { Solid Organ } \\
\text { Injury (SOI) }\end{array}$ & $\begin{array}{c}\text { Pelvic Fracture + } \\
\text { Rib Fracture, } \mathbf{n = 2 4}\end{array}$ & $\begin{array}{c}\text { Pelvic Fracture } \\
\text { Alone, } \mathbf{n = 1 0 6}\end{array}$ \\
\hline Present (n= 35) & $16(66.7 \%)$ & $23(21.7 \%)$ \\
\hline Absent (n= 95) & $8(33.3 \%)$ & $83(78.3 \%)$ \\
\hline \multicolumn{2}{|c|}{ Table 4. Distribution of Cases associated with } \\
Solid Organ Injury \\
\hline
\end{tabular}

The most common comorbid condition associated with pelvic fractures is osteoporosis in $46(35.4 \%)$ followed by hypertension in 33 (25.4\%), diabetes mellitus in 24 (18.5\%), atrial fibrillation in 21 (16.2\%), congestive cardiac failure in 15 (11.5\%), coronary artery disease in 14 (10.7\%), old myocardial infarction in $9(6.9 \%)$ and obesity in 7 (5.4\%) cases (Table 5).

\begin{tabular}{|c|c|c|}
\hline Comorbid Condition & $\mathbf{n = 1 3 0}$ & \% \\
\hline Osteoporosis & 46 & 35.4 \\
\hline Hypertensive disease & 33 & 25.4 \\
\hline Diabetes mellitus & 24 & 18.5 \\
\hline Atrial fibrillation & 21 & 16.2 \\
\hline Congestive heart failure & 15 & 11.5 \\
\hline Coronary artery disease & 14 & 10.7 \\
\hline Old myocardial infarction & 9 & 6.9 \\
\hline Obesity & 7 & 5.4 \\
\hline Table 5. Prevalence of Comorbidities in Patients \\
with Pelvic Ring Fractures \\
\hline
\end{tabular}

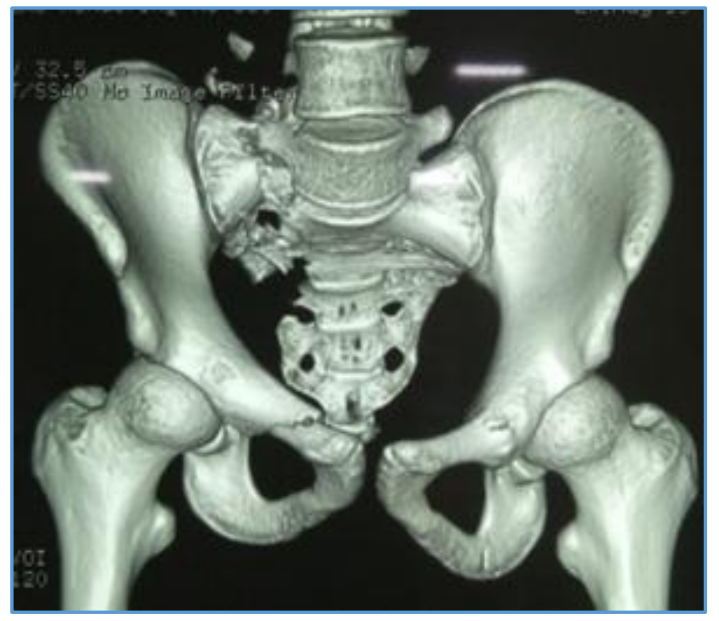

Image 1. Fracture of Right Pubis and Right Side of Sacrum

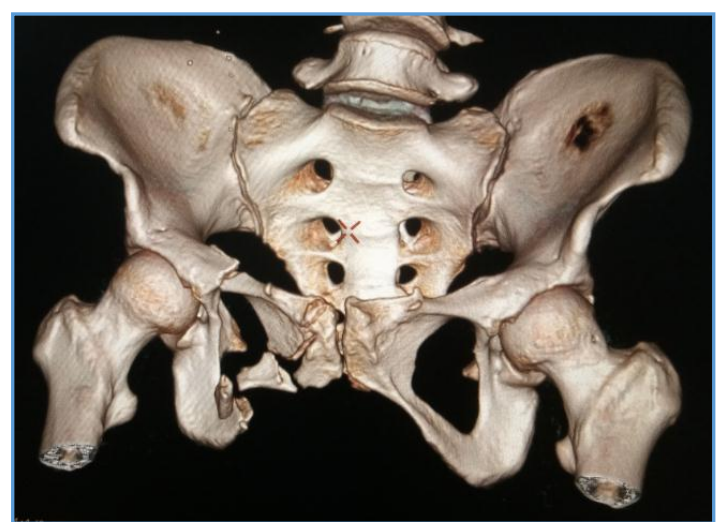

Image 2. Fracture of Right Pubis, Superior Pubic Ramus, Ischium and Ischiopubic Ramus

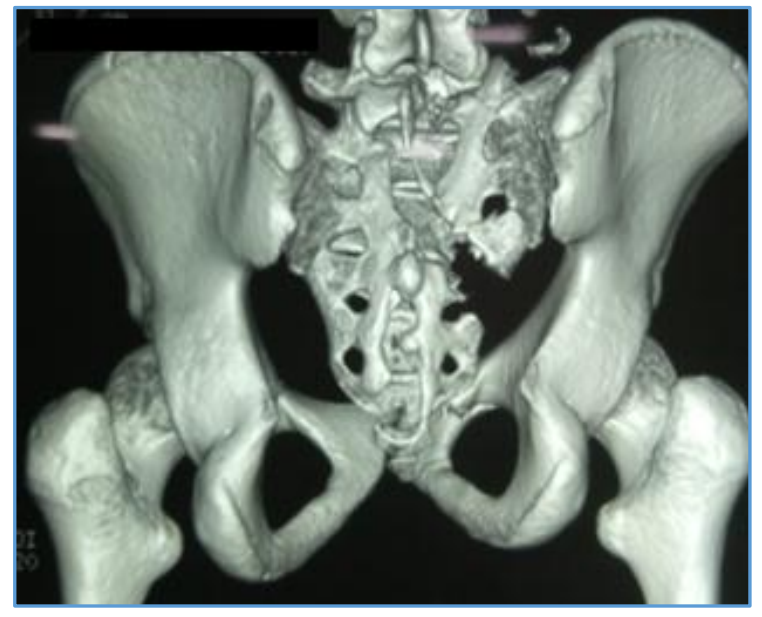

Image 3. Fracture of the Sacrum

\section{DISCUSSION}

Trauma accounts for approximately 1 in 10 deaths worldwide. The presence of a pelvic fracture increases the mortality risk. ${ }^{9}$ In contrast to an overall decline in trauma mortality, complex pelvic ring injuries remain associated with a significant risk of death. ${ }^{10}$ The key elements in managing patients with pelvic fractures are swift and adequate resuscitation, reversal of shock and acidosis, and rapid control of haemorrhage to facilitate survival of these patients. 11

From the viewpoint of pre-hospital emergency medicine, a greater proportion of pelvic fractures not of a lifethreatening status, but combined with other injures need more attention and comprehensive recognition.

In this study, we observed pelvic fracture in $6.1 \%$ of patients presented to emergency department with fracture at any site of the body. Similarly, RP Gonzalez et al ${ }^{12}$ found pelvic fracture in $4.5 \%$ of their trauma patients. Pohlemann T et al ${ }^{2}$ and Balogh $\mathrm{Z}$ et al ${ }^{13}$ also studied pelvic fractures in $2 \%$ and $8 \%$ of all fractures.

We conducted this study on 130 diagnosed cases of pelvic fracture. We studied that incidence of pelvic fracture was more in females, 81 (62.3\%) compared to males 49 (37.7\%). Females sustained significantly more injuries as compared to males with an overall ratio of 1.6: 1 . Similarly, Leonard T Buller et $\mathrm{al}^{14}$ have also observed pelvic fracture more common in females $(69.7 \%)$ than males $(30.3 \%)$ in the ratio of 2.3: 1. Nan-Ping Yang et al ${ }^{15}$ have also recorded higher fracture rate in females when compared to males. Silke Andrich et al 16 also observed pelvic fractures more common in women (82\%) than men (18\%) (4.5: 1).

We observed majority of fractures in the elderly age group of $>75$ years, $66(50.8 \%)$ followed by $<35$ years, 25 (19.2\%), 56 - 75 years, $23(17.7 \%)$ and $36-55$ years, 16 $(12.3 \%)$. In both the sex we found that incidence of fracture was more in same $5^{\text {th }}, 6^{\text {th }}$ and $7^{\text {th }}$ decade of life. We found that the average age of presentation was $66.5 \mathrm{yrs}$. In accordance to us, Leonard $\mathrm{T}$ Buller et al studied the mean age of patients with a pelvic ring fracture of 64.5 years and more patients were in $6^{\text {th }}$ and $7^{\text {th }}$ decades. Similar to us, Nan-Ping Yang et al found the elderly patients (aged 65 years or more) were noted to have a significantly increased incidence of pelvic fracture. Similarly, Silke Andrich et al also studied the incidence of pelvic fractures were more in age group $>75$ years in comparison to $<75$ years $(95.2 \%$ vs. $4.8 \%)$ and the 
mean age of affected persons was $80.3 \pm 8.7$ years. In contrast to us, Ramesh K Sen et al studied the mean age of the patients with pelvic fracture of $(29.0 \pm 2.6)$ years.

In our study most common site of pelvic fractures observed was in the pubis, about 88 cases $(67.7 \%)$ followed by ilium 83 (63.8\%), ischium 61 (46.9\%), sacrum 21 (16.2\%) and multiple pelvic ring fracture in 23 (17.8\%) cases. Similarly, Leonard $\mathrm{T}$ Buller et al observed the most frequent location of pelvic fractures was at pubis. Though we observed sacrum as the least common site of fracture, they found ischium as the least common site of fracture. Nan-Ping Yang et al also observed the most common pelvic fracture pattern to be fractures of the pubis, ilium or ischium.

In this study, we observed road traffic accidents as the most common cause of pelvic fracture seen in 73 (56.2\%) cases followed by pedestrian hit by car in $22 \%$ and fall from height in $13 \%$ cases. In accordance to us Nan-Ping Yang et al also studied $62 \%$ of the recorded cases resulted from transport accidents and 10\% from falling accidents. Ammar Al-Hassani et al ${ }^{17}$ also found motor vehicle crash (45\%) and fall from height (30\%) were the most common mechanism of pelvic injury, others being pedestrian hit by motor vehicle (10\%), stuck by falling object (6\%) and others (9\%). Laszlo Toth et al ${ }^{18}$ also studied road traffic accidents as the most common cause of pelvic fracture seen in $60 \%$ cases followed by fall from height in 29 (22.3\%), pedestrian hit by car in 18 $(13.8 \%)$ and assault in $6(4.6 \%)$. In accordance to us, María Roxana et al $^{19}$ found the main mechanism of trauma was traffic accidents (80\% of cases) followed by falls from height $(16 \%)$ and injury caused by heavy object falling into the lower limbs (4\%). They also observed that among traffic accidents, the most common type was running over by car (40\%) followed by accidents involving motorcycle passenger (25\%), running over by a bus or truck $(20 \%)$ and accidents involving car occupants (10\%) and cyclists hit by bus (5\%). In contrast to us, Ramesh $\mathrm{K}$ Sen et al ${ }^{20}$ studied the most common cause of pelvic fracture being automobile pedestrian collisions $(36.6 \%)$ followed by motor vehicle collisions (30.6\%), fall from height $>15$ feet $(19.3 \%)$, fall from height $\leq 15$ feet $(8.3 \%)$ and other types of trauma (5.6\%).

In this study, we observed that pelvic fractures are associated with other injuries in 75 (57.7\%) cases. Most commonly associated injury was urinary bladder and urethral injury in 45 (34.7\%) cases followed by solid organ injury (SOI) in 35 (26.9\%), chest trauma with rib fractures in $24(18.5 \%)$, haemodynamic instability in 19 (14.6\%), lung contusion in $15(11.5 \%)$ cases and other injuries observed were acetabular fracture, femur fracture, head injury and facial bone fractures. Among the solid organs, most common organ involved was splenic in $16(12.3 \%)$ followed by liver in $12(9.2 \%)$ and kidney in $8(6.2 \%)$ cases. Epidemiologic studies have reported that $12 \%$ to $62 \%$ of patients with pelvic fractures had additional injuries to the thorax, brain, long bones and abdominal organs to include the genitourinary system, spine and the peripheral nervous system. ${ }^{21,22}$ Tomislav Pejcic et al ${ }^{23}$ studied urethral injuries in $46 \%$ of patients and urinary bladder trauma in $12 \%$ of patients. In contrast to us, Nan-Ping Yang et $\mathrm{al}^{1}$ observed the most common injuries associated with pelvic fractures were fractures of lower limbs (21.50\%) followed by fractures of the spine/ trunk (20.97\%) and fractures of upper limbs $(18.18 \%)$, fracture of the skull or intracranial injury $(17.59 \%)$, internal injury of the abdomen and pelvis (11.00\%) and internal injury of the chest (7.20\%).

In contrast to us Leonard $\mathrm{T}$ Buller et al observed acetabular fracture in $8.9 \%$, femur fracture in $6.7 \%$, femoral neck fracture in $3.8 \%$, head trauma in $0.7 \%$, head/ face trauma in $0.7 \%$ and chest/ trunk trauma in $0.1 \%$ of cases. In contrast to us María Roxana et al found $92 \%$ of patients had Traumatic Brain Injury (TBI) and $40 \%$ had haemodynamic instability, genitourinary in $32 \%$, orthopaedic (other) in $32 \%$, abdominal in 28\%, neurological in 28\%, thoracic in $16 \%$ and vascular in $8 \%$ of cases. In Gänsslen's multicentre review, ${ }^{24}$ of the 312 pelvic fracture patients with associated injuries $63 \%$ had injury to the bladder or urethra, $35 \%$ had associated head injuries, $24 \%$ had nerve injuries and $20 \%$ had intestinal injuries. Basta and associates 25 found the location and displacement of anterior pelvic fractures were predictive of the presence of urethral injury in a case control study of pelvic fracture patients with and without associated urethral injury. They observed that each millimetre of pubic diastasis or inferomedial pubic bone fracture fragment displacement was associated with a $10 \%$ increased risk of urethral injury.

In this study, we observed incidence of solid organ injury was more in patients associated with rib fracture in comparison to patients with only pelvic fracture $(66.7 \%$ vs. $21.7 \%$ ) and the overall incidence of Solid Organ Injury (SOI) was $26.9 \%$. Similar to our study Ammar Al-Hassani et al found SOI predominantly in patients with concurrent rib fracture and pelvic fracture compared to ribs or pelvic fractures alone ( $42 \%$ vs. $26 \%$ vs. $15 \%$, respectively). They studied the most common injured organ was spleen followed by liver and kidney. The overall incidence of SOIs in their study was $22 \%$. Early identification of patients with haemorrhage is critical in management. Although, evaluation of patients with blunt abdominal injury typically involves a Focused Assessment with Sonography for Trauma (FAST) exam in patients with pelvic fractures. A negative exam does not rule out intraperitoneal haemorrhage. ${ }^{26}$

The most common comorbid condition associated with pelvic fractures is osteoporosis in 46 (35.4\%) followed by hypertension in 33 (25.4\%), diabetes mellitus in 24 (18.5\%), atrial fibrillation in 21 (16.2\%), congestive cardiac failure in 15 (11.5\%), coronary artery disease in 14 (10.7\%), old myocardial infarction in $9(6.9 \%)$ and obesity in $7(5.4 \%)$ cases.

\section{CONCLUSION}

Pelvic fractures are often the result of high-energy trauma in young individuals and low-energy injury in older people. There are a number of areas of uncertainty in the initial triage and management of patients with pelvic ring fractures. While it is clear that haemodynamically unstable patients have a higher mortality, the source of bleeding (Venous, arterial or bony) is typically not clear. A better understanding of the source would help determine if patients would be more likely to benefit from emergent arterial angiography or pelvic stabilisation. The concurrent clinical findings of fractures of the lower ribs and pelvic fracture after blunt trauma pose a high risk for intra-abdominal solid organ injury. 


\section{REFERENCES}

[1] Hauschild O, Strohm PC, Culemann U, et al. Mortality in patients with pelvic fractures: results from the German pelvic injury register. Journal of Trauma Injury, Infection and Critical Care 2008;64(2):449-55.

[2] Pohlemann T, Tscherne H, Baumgartel F, et al. Pelvic fractures: epidemiology, therapy and long-term outcome. Overview of the multicenter study of the Pelvis Study Group. Unfallchirurg 1996;99(3):160-7.

[3] Benzinger P, Becker C, Kerse N, et al. Pelvic fracture rates in community-living people with and without disability and in residents of nursing homes. J Am Med Dir Assoc 2013;14(9):673-8.

[4] Chien LC, Cheng HM, Chen WC, et al. Pelvic fracture and risk factors for mortality: a population-based study in Taiwan. Eur J Trauma Emerg Surg 2010;36(2):131-7.

[5] Nanninga GL, de Leur K, Panneman MJ, et al. Increasing rates of pelvic fractures among older adults: The Netherlands, 1986-2011. Age Ageing 2014;43(5):648-53.

[6] Holstein JH, Culemann U, Pohlemann T, et al. What are predictors of mortality in patients with pelvic fractures? Clinical Orthopaedics and Related Research 2012;470(8):2090-7.

[7] Sauerland S, Bouillon B, Rixen D, et al. The reliability of clinical examination in detecting pelvic fractures in blunt trauma patients: a meta-analysis. Archives of Orthopaedic and Trauma Surgery 2004;124(2):123-8.

[8] World Health Organization. Global Health and Aging. National Institute on Aging, National Institute of Health

2011.

http://www.who.int/ageing/publications/global_heal th/ en/. Accessed January 7, 2015.

[9] Frevert S, Dahl B, L"onn L. Update on the roles of angiography and embolisation in pelvic fracture. Injury 2008;39(11):1290-4.

[10] Pohlemann T, Stengel D, Tosounidis G, et al. Survival trends and predictors of mortality in severe pelvic trauma: estimates from the German Pelvic Trauma Registry Initiative. Injury 2011;42(10):997-1002.

[11] Eckroth-Bernard K, Davis JW. Management of pelvic fractures. Current Opinion in Critical Care 2010;16(6):582-6.

[12] Gonzalez RP, Fried PQ, Bukhalo M. The utility of clinical examination in screening for pelvic fractures in blunt trauma. Journal of the American College of Surgeons 2002;194(2):121-5.

[13] Balogh Z, King KL, Mackay P, et al. The epidemiology of pelvic ring fractures: a population-based study. J Trauma 2007;63(5):1066-73, discussion 1072-3.
[14] Buller LT, Best MJ, Quinnan SM. A Nationwide analysis of pelvic ring fractures: incidence and trends in treatment, length of stay and mortality. Geriatric Orthopaedic Surgery \& Rehabilitation 2016;7(1):9-17.

[15] Yang NP, Chan CL, Chu D, et al. Epidemiology of hospitalized traumatic pelvic fractures and their combined injuries in Taiwan: 2000-2011 National Health Insurance Data Surveillance. Article ID 878601, Biomed Research International 2014;2014: p. 9.

[16] Andrich S, Haastert B, Neuhaus E, et al. Epidemiology of pelvic fractures in Germany: considerably high incidence rates among older people. PLoS One 2015;10(9):e0139078.

[17] Al-Hassani A, Afifi I, Abdelrahman H, et al. Concurrent rib and pelvic fractures as an indicator of solid abdominal organ injury. International Journal of Surgery 2013;11(6):483-6.

[18] Toth L, King KL, McGrath B, et al. Factors associated with pelvic fracture-related arterial bleeding during trauma resuscitation: a prospective clinical study. J Orthop Trauma 2014;28(9):489-95.

[19] Maria RVG, Susana RB, Miguel A, et al. Pelvic injury in childhood: What is its current importance? Acta Ortop Bras 2016;24(3):155-8.

[20] Sen RK, Gopinathan NR, Tamuk T, et al. Predictors of early outcome in unstable pelvic fractures. Chinese Journal of Traumatology 2013;16(2):94-8.

[21] Demetriades D, Karaiskakis M, Toutouzas K, et al. Pelvic fractures: epidemiology and predictors of associated abdominal injuries and outcomes. J Am Coll Surg 2002;195(1):1-10.

[22] Durkin A, Sagi HC, Durham R, et al. Contemporary management of pelvic fractures. Am J Surg 2006;192(2):211-23.

[23] Pejcic T, Loncar Z, Rafailovic D, et al. Genitourinary injuries associated with pelvic fractures. Acta Chir Lugosl 2013;60(2):117-20.

[24] Gänsslen A, Pohlemann T, Paul C, et al. Epidemiology of pelvic ring injuries. Injury 1996;(27 Suppl 1):S-A1320.

[25] Basta AM, Blackmore CC, Wessells H. Predicting urethral injury from pelvic fracture patterns in male patients with blunt trauma. J Urol 2007;177(2):571-5.

[26] McCormack R, Strauss EJ, Alwattar BJ, et al. Diagnosis and management of pelvic fractures. Bulletin of the NYU Hospital for Joint Diseases 2010;68(4):281-91. 